\title{
Sin riesgo no hay conocimiento ${ }^{1}$
}

\author{
Xabier Insausti \\ Universidad del País Vasco
}

\section{Resumen}

Este artículo pone en el punto de mira una pequeña reflexión de Ernst Bloch desarrollada en un libro titulado Avicena y la izquierda aristotélica. El artículo usa este texto como cañamazo para desarrollar algunas reflexiones que van más allá del texto de Bloch, pero que al autor le parecen estar en consonancia con las ideas de este filósofo. Hay dos líneas fundamentales en la filosofía, ambas desarrolladas a partir de Aristóteles. Bloch entiende, como no podía ser de otro modo, que solo la denominada "izquierda" aristotélica es la verdaderamente filosófica, por cuanto defiende un pensamiento libre, sin coacciones ni restricciones, mientras que la otra línea compromete la filosofía misma por sus compromisos con intereses ajenos a ella. Entendemos que la modernidad recoge este testigo y lo lleva adelante, a pesar de las dificultades encontradas. Se trata, por tanto, de un canto a la libertad filosófica y un homenaje a cuantos han puesto en riesgo su vida misma en esta empresa. Solo en el fondo de la filosofía se halla la libertad. Esto conlleva, a veces, a riesgos.

\section{Palabras clave:}

\begin{abstract}
This article highlights a small reflection by Ernst Bloch developed in a book entitled Avicenna and the Aristotelian Left. The article uses this text as a canvas to develop some reflections that go beyond Bloch's text but that seem to the author to be in line with the ideas of this philosopher. There are two fundamental lines in philosophy, both developed from Aristotle. Bloch understands, how could it be otherwise, that only the so-called Aristotelian "left" is the truly philosophical one, insofar as it defends free thought, without constraints or restrictions, while the other line compromises philosophy itself due to its commitments to interests oblivious to it. We understand that modernity picks up this witness and carries it forward despite the difficulties encountered. It is therefore a hymn to philosophical freedom and a tribute to
\end{abstract}

1 Este artículo es una versión ampliada de otro anterior. 
those who have put their very lives at risk in this work. Only at the bottom of philosophy is freedom found. This sometimes carries risks.

Key words: Ernst Bloch, izquierda aristotélica, modernidad, empresa filosófica.

\section{Introducción}

Worin der Gedanke hinaus ist über das, woran er widerstehend sich bindet, ist seine Freiheit. Sie folgt dem Ausdrucksdrang des Subjekts. Das Bedürfnis, Leiden beredt werden zu lassen, ist Bedingung aller Wahrheit. Denn Leiden ist Objektivität, die auf dem Subjekt lastet; was es als sein Subjektivstes erfährt, sein Ausdruck, ist objektiv vermittelt. (Adorno, Negative Dialektik, GS 6, 29)

Todo ser humano tiende por naturaleza $(\phi v \sigma \varepsilon i)$ a conocer. Así, comienza el primer libro de la Metafísica de Aristóteles. La tendencia a conocer está, por tanto, inscrita en la naturaleza humana. Ella ha sido el motor tractor tanto del sujeto como de la humanidad. Si el ser humano renuncia a conocer, renuncia a su naturaleza, renuncia a sí mismo. Conocer tiene, por tanto, que ver con el ser mismo del ser humano, no con algún accidente o interés más o menos caprichoso o prescindible. Conocer es seguir la "Ausdrucksdrang" (el impulso, la necesidad de expresarse, de desarrollarse) del sujeto.

El deseo de conocer ha llevado adelante a la humanidad, la ha llevado a progresar, a avanzar. No en el sentido ingenuo de la Ilustración, según la cual cualquier avance puramente técnico o instrumental, aunque sea ciego, sería positivo y bueno, sino en un sentido crítico, según el cual todo paso adelante supone un paso hacia atrás, y obliga a reconsiderar las premisas supuestas. Avanzar conlleva siempre un componente crítico y utópico que va más allá de una mera instrumentalización. 
Este impulso por conocer llevó, por ejemplo, a Magallanes (ahora que celebramos el 500 aniversario de su viaje) a emprender la entonces arriesgada empresa de dar la vuelta al mundo, de navegar hacia el Oeste, buscando la tierra de las especias. Quería saber si era posible llegar a dichas islas navegando en la dirección contraria a la habitual y conocida. Así supimos definitivamente que la Tierra era redonda. Stefan Zweig (en Magallan Der Mann und seine Tat) nos lo presenta como un idealista, emprendedor, seguro de sí mismo, dispuesto a arriesgarlo todo para demostrar lo que intuía. Un carácter semejante al de Ulises, el griego. Aunque Magallanes mismo no consiguió llegar a su Ítaca (a Sevilla, de donde partió), el viaje le dio la razón. Fue el suyo el primer gran viaje en el imaginario moderno, tanto o más arriesgado y complicado que los de Colón. Con su viaje comienza, pues, la Modernidad, como la entiende Zweig. Se repite con él de nuevo la hazaña de Ulises. Así la podríamos reinterpretar con Horkheimer y Adorno (Dialéctica de la Ilustración). La astucia de Magallanes no es menor que la de Ulises. Su instinto le guía. Las dificultades objetivas son las de su tiempo. Y él las conocía muy bien. Y supo hacerles frente, como Ulises. También, Magallanes escuchó el canto de las sirenas que le insistían en renunciar a su empresa en determinadas circunstancias difíciles, pero supo desoír esas voces. Supo imponer su instinto a la tentación cómoda de lo seguro. Arriesgó su vida para ello y salió victorioso. Llegó a su Ítaca, aunque lo pagó caro, pues, como Moisés, vio la tierra prometida, pero no le fue dado adentrarse en ella. Aunque supo que había conseguido su propósito, tampoco él pudo saborear los frutos de su éxito. Su final trágico es, por ello, incluso más heroico que el de Ulises.

Por esa misma época, exactamente en 1507, Copérnico (Copernicus en latín) escribía el libro De revolutionibus orbium coelestium (Sobre la rotación de los cuerpos celestes). Era el primer occidental que se atrevió a poner al Sol y no a la Tierra en el centro del sistema planetario, contra Aristóteles y la Biblia. Su libro se publicó más tarde, en 1543, el mismo año de su muerte, pero de forma póstuma, lo cual lo salvó de sinsabores seguros, pues su libro fue colocado en la lista de libros prohibidos (Index librorum prohibitorum) por la Iglesia y allí permaneció hasta 1757. Unos años después, exactamente en 1548, nacía Giordano 
Bruno, quien pronto vio en Copérnico un genio, lo consideró incluso un emisario de Dios, enviado a traer luz a la Tierra, pero Bruno, por precaución, formuló como hipótesis su certeza de que existían cuerpos celestes alrededor de los cuales se movía la Tierra, y no como una convicción, pero la estratagema no le valió. Perseguido como hereje en su propio país (Italia) huyó, primero a Londres, luego a Wittenberg, pero cometió la imprudencia de volver a Italia, donde fue detenido y pasó siete ańos en la cárcel. Hasta que, en 1600, fue quemado en Roma después de haber sido expulsado de la Iglesia.

Un destino parecido tuvo otro ilustre hijo de Italia, el florentino Galileo Galilei (1564-1642). Construyó un telescopio con el que pudo ver que las estrellas no giraban alrededor de la Tierra, sino que era otro el centro de gravedad, "quizás” el Sol. Quedaba, así, corroborado por la "intuición” (Anschauung, en alemán), es decir, demostrado científicamente, lo que Copérnico defendió. Anschauung es un concepto relacionado con la vista. "Intuor" en latín, es decir, "veo": la prueba de la verdad, de la ciencia. Así comienza el mismo Kant su primera Crítica: "Sea como sea nuestro modo de relacionarnos con el mundo la intuición es la instancia primera que nos pone en contacto con ella" (Estética Transcendental). Por cierto, Marx criticará en su primera Tesis sobre Feuerbach, que la Modernidad ha concebido, según su interpretación, lo que es la intuición de un modo erróneo, pues la ha entendido solo "de un modo subjetivo", no de un modo objetivo, práctico, es decir, no como praxis, como acción. En todo caso, a la pregunta de si debemos creer a la Biblia que dice que la Tierra se halla en el centro del universo o a la matemática que dice que no, Galileo responde que debemos creer a la Biblia, pero cuando la matemática dice otra cosa debemos cambiar nuestra interpretación de la Biblia. La matemática tiene razón siempre, declara la Modernidad. La teología debe servir a la matemática. A pesar de que un discípulo de Galileo llegó al papado (con el nombre de Urbano viII), Galileo no se vio libre de persecución: fue llamado a Roma donde fue obligado, bajo amenaza de tortura, a reconocer que Copérnico se equivocaba con su teoría heliocéntrica. Era el año 1633. Tras una breve estancia en la cárcel, fue recluido en su casa, donde se le prohibió hablar y escribir sobre 
sus teorías. Mathias Bernegger consiguió su manuscrito (escrito en italiano) y lo tradujo al latín, la lengua universal de los intelectuales de entonces, y lo salvó así de una más que probable desaparición.

Para todos ellos vale lo que afirma Fichte con respecto a la persecución a la que se vio sometido en relación con la famosa "polémica del ateísmo": "Nunca he creído que estén persiguiendo mi supuesto ateísmo; lo que persiguen en mí es a un pensador libre y a un convencido demócrata; les asusta como un fantasma la independencia que intuyen que mi filosofía despierta”. Este es el verdadero espíritu de la Modernidad, no distinto que el defendido por Aristóteles, aunque, ¿de qué Aristóteles hablamos?

Estos héroes modernos no son los primeros que se enfrentan a las enseñanzas dogmáticas de quienes tratan de imponer doctrinas basadas en supuestos sospechosos, no críticos. Más bien heredan el espíritu crítico que otros anteriores a ellos ya habían preparado y enseñado. A partir de Aristóteles se abren dos caminos que habría de recorrer la filosofía (al menos, la occidental) y que Ernst Bloch presenta en su obra Avicenna und die Aristotelische Linke, 1952, uno por la izquierda y otro por la derecha. El libro de Bloch comienza con una cita en alemán, que pretende resumir todo el espíritu de la obra: "Entwicklung ist eductio formarum ex materia" (Avicena/Averroes) y que podríamos traducir de la siguiente forma: El desarrollo es darle forma a la materia, arrancarle formas a la materia, "formar" la materia. La materia es, pues, el punto de partida desde el que se "forma" todo lo demás.

El gran precursor de la izquierda aristotélica es, según Bloch, Avicena (980-1037), el cual desarrolla una filosofía "no cristiana" ("unchristlich", Bloch 1963, 11) a partir de Aristóteles, seguida directamente por Avicebrón, y que volverá, años después, a Europa de la mano, primero, de Giordano Bruno y, luego, de Spinoza. "Hay una línea que lleva de Aristóteles no a Tomás de Aquino y al espíritu del más allá, sino a Giordano Bruno y a la materia total floreciente" ("Es gibt eine Linie, die von Aristoteles nicht zu Thomas führt und zum Geist 
des Jenseits, sondern zu Giordano Bruno und der blühenden Allmaterie". (Bloch 1963, 11-12). Avicena era médico, no monje. Del mismo modo que los demás pensadores islámicos importantes, vivía por tanto ocupado en los problemas materiales y corporales de la gente, no en un más allá abstracto e incorpóreo, y pensaba, como no podía ser de otro modo, de un modo naturalístico, científico. "Ibn Sina war Arzt, er ist kein Mönch gewesen. Sowenig wie die anderen bedeutenden islamischen Denker, sie lebten weltlich und dachten naturwissenschaftlich" (Bloch 1963, 12).

El hecho de que la filosofía griega floreciera en la sociedad islámica fue posible, porque era una moderna sociedad, abierta al mercado y al comercio mundial (sus centros eran las ciudades de Petra y Bostra), mientras la europea se centraba en erigir conventos y preparar clérigos inútiles, una sociedad (la islámica) dispuesta a absorber y asimilar la cultura y las posibles aportaciones de los diversos lugares con los que comerciaba. Y la cultura y la filosofía griegas les interesó sobremanera, porque veían en ellas una posibilidad de progreso. Además del comercio, el libro era, sin duda, un objeto preciado en Oriente, con una larga tradición (cfr. Bloch, 1963, p. 14). La filosofía no era un elemento extraño, no era ninguna rara "planta exótica" (Bloch, 1963, p. 15). Tenía una larga tradición greco-siria. Una tradición en la que los pensadores islámicos más importantes fueran médicos, no monjes; naturalistas y no teólogos. "Das alles mitin erklärt und umgibt die Eigenschaft der bedeutendsten islamischen Denker: Arzt, nicht Mönch, Naturalist, nicht Theologe zu sein" (Bloch, 1963, p. 15). Entendieron, como hombres de ciencia que eran, que la filosofía les podía ayudar a comprender mejor el mundo y la naturaleza. Roger Bacon llamó a la ciencia árabe "scientia experimentalis" (cuando Bacon estudió en París, estudiar a Aristóteles estaba prohibido, porque solo era posible a través de autores islámicos). YWilhem von Humboldt afirmó que fueron los árabes los inventores del "experimento". La libertad de espíritu que reinaba en Oriente (Bagdad era el centro cultural) se extendió hasta Córdoba en Occidente.

Los pensadores árabes entendieron que la sabiduría es superior a la fe, la cual se absorbe - así traduce Ortega la "Aufhebung" alemana-y se diluye en la filosofía. Se "supera" (aufhebt) en ella. Quien sabe no 
necesita la fe. Aristóteles (no Mahoma) es la encarnación superior del espíritu humano para Avicena. Para los escolásticos cristianos, por el contrario, Aristóteles será (a partir de 1200) el precursor de Cristo. Para los filósofos islámicos no es un precursor de Cristo ni de Mahoma, sino la representación de la razón humana misma, de la filosofía, de la sabiduría; el filósofo es el modelo a seguir, porque encarna la sabiduría misma, la ciencia. Del lado de la derecha, en cambio, Alberto Magno y sobre todo Tomás de Aquino cambiarán el sentido del binomio fe-saber desarrollado por los islamistas: la filosofía se debe arrodillar ante la fe, su papel es expresarla correctamente. Aunque bien es preciso subrayar que la cultura islámica no se opuso a la mística, sino que tuvo incluso una deriva acorde al espíritu de los filósofos islámicos, es decir, contra la ortodoxia religiosa y la iglesia, en la que se unieron los sufíes con los pensadores islamistas. Una deriva que llega directamente hasta los místicos europeos Joachim von Fiore (1135-1202) y Meister Eckhart (1260-1328).

Avicena escribió un cuento alegórico: Hajj ibn Jakzan (traducido al alemán como Der Lebende, Sohn des Wachenden; El viviente hijo del vigilante), en el que el autor presenta un personaje que llega al conocimiento en total aislamiento y soledad. Ibn Tofail (Abentofail), siguiendo a su maestro Avicena, escribirá posteriormente una obra (considerada la primera novela árabe, incluso la primera novela filosófica) con el mismo título que será traducida primero al latín en 1671 con el significativo título de Philosophus autodidactus y luego al alemán por Eichhorn en 1783 con el título Der Naturmensch. Existe una edición castellana con el título El filósofo autodidacta (en 1900, con prólogo de M. Menéndez y Pelayo: El filósofo autodidacto, de Abentofail. Prólogo de la traducción hecha por D. Francisco Pons Boigues, e impresa en Zaragoza, el año 1900, Colección de Estudios árabes).

La obra no solo adelanta la idea romántica de un Robinson que debe sobrevivir con sus propias fuerzas, sino refuerza la idea básica de la Ilustración: que el ser humano no necesita ninguna fe fuera de su razón. Es por tanto una verdadera precursora de Robinson Crusoe, Emilio o de la Educación, Zadig de Voltaire o de Mowgli en El libro de la Selva. También influyó en El Criticón de Baltasar Gracián (1651, 
1653 y 1657), tan del gusto de Schopenhauer y Nietzsche. Incluso, en el libro de Rancière, El maestro ignorante, resuena esta idea o hasta en la pedagogía liberadora de Paolo Freire o de cualquiera que considere al ser humano capaz de descubrir por sí mismo, sin ayuda externa, lo que su razón le dicta. Es evidente que estas ideas no podían ser del agrado de los pensadores escolásticos, que enseńaban que la Iglesia y la Teología eran doctrinas que se deben obedecer y seguir, incluso aunque no se entiendan, es decir, ciegamente: una idea recurrente en toda la derecha escolástica.

Solamente nos estamos limitando a algunas notas del libro de Bloch, sin pretensión de agotar lo que el mismo autor, por su parte, tampoco desarrolla en toda su extensión. Lo que Bloch descubre entre los que llama izquierdistas, dice, son "correspondencias", no "coincidencias" entre diferentes y diversos pensadores: un interés común en un más acá (frente al interés por un más allá de los escolásticos), un esfuerzo por rescatar, repensar el nous (voũs) aristotélico en un naturalismo más radical incluso que el que le imprimió el mismo Aristóteles (y, por supuesto, frente y en oposición al trascendentalismo que le imprimieron los escolásticos), y que tanto daño ha hecho y sigue haciendo en Occidente. Basta recordar que, en su nombre, se expulsó a judíos y musulmanes de Espańa, y que la negra sombra de este error y terror histórico llegó hasta nuestros días.

\section{II}

Bloch entiende que Aristotéles deja cuestiones fundamentales de su filosofía en una indefinición que será la que hará posible que se abran ambos flancos, lo cual va a ser decisivo no solo para la filosofía, sino para el destino general de la cultura occidental. Desde el comienzo hubo fuertes tensiones entre los intérpretes de Aristóteles. Aunque Avicena sea el gran precursor de la izquierda aristotélica, antes hubo seguidores directos de Aristóteles que lo interpretaron claramente desde posiciones abiertamente naturalísticas.

El mismo Estratón de Lámpsaco (340-268 a. C.), sucesor de Teofrasto (el cual sucedió al mismo Aristóteles en la dirección del 
Liceo), le dio una impronta radical a la escuela peripatética fundada por Aristóteles. Dios es para Estratón simplemente la fuerza inconsciente de la naturaleza. Trató de reemplazar la teleología por una explicación puramente física de los fenómenos. Cicerón afirma lo siguiente de Estratón: "Omnem vim divinam in natura sitam esse": toda la fuerza divina se halla en la naturaleza, no en un más allá de ella misma. Llamado el "físico", fue el primero, por tanto, que le dio un giro claramente naturalista a Aristóteles.

Luego, Alejandro de Afrodisias (cuya datación es desconocida, ya que solo sabemos que vivió a finales del siglo II) seguiría esta línea que retomará Avicena y desarrollará Avicebrón con su idea de una "materia universalis". Las obras de Alejandro, comentador de Aristóteles, al que trata de depurar del sincretismo de algunos contemporáneos, fueron muy elogiadas entre los árabes. Su influencia llegará a Giordano Bruno que considera a la materia como una vida-total (All-Leben) que fecunda y es fecundada (befruchtend-befruchtete) al mismo tiempo: la materia divina misma se absorbe en la potencialidad activa de la materia (cfr. Bloch, 1963, pp. 32-33).

Por el contrario, la derecha aristotélica que lleva hasta Tomás de Aquino aleja el teísmo del nous puro, ya de por sí alejado en Aristóteles mismo, todavía más, de la materia, de modo que la materia se queda en mera potencialidad, es decir, en la mera incapacidad de salir por sí misma de su "ser-en-posibilidad", su "dunamei on" para alcanzar el mundo. El abismo entre ambos extremos (el nous puro y la materia) se agranda por la derecha; se acorta, hasta se suprime, por la izquierda.

Tres son los aspectos decisivos de la filosofía de Aristóteles en que se centra Bloch para definir las diferencias entre una izquierda y una derecha aristotélica. En primer lugar, en lo que hace al cuerpo y alma. La línea naturalista tiende a fundirlas en uno; la escolástica, a separarlas. Para estos últimos, el cuerpo es la cárcel del alma, está caída en él. Por ello, hay que castigar al cuerpo, reprimirlo, anularlo. El cuerpo es la causa del pecado. Por ello, es imprescindible para la derecha que el cuerpo sobreviva a la muerte, para ser castigado en el infierno. La cuestión fundamental se reduce por tanto a creer o no en la resurrección del cuerpo. La consecuencia es evidente. Si no hay resurrección de los 
cuerpos, a la Iglesia se le sustrae este poderoso recurso e instrumento para sus influjos e intereses clericales de dominación y control. Por ello, ha perseguido a todo el que niega la resurrección de los cuerpos.

En segundo lugar, en lo que se refiere a la razón universal y al entendimiento individual. Para Aristóteles, el entendimiento individual es pasivo, pegado al cuerpo por el hábito (la costumbre), se halla a disposición del material. Por el contrario, la razón universal es activa, es la forma propia, la fuerza efectiva del entendimiento, libre del hábito del cuerpo correspondiente. Es un elemento del espíritu divino. Ambas se hallan separadas en Aristóteles, no se da una unidad. En Avicena y Averroes, por el contrario, la razón activa es el lugar de la unidad del intelecto en el género humano. Es lo humano-universal en los individuos particulares; y ello como filosofía, no como religión. La unidad del género humano es la "unitas intellectus" basada en la tolerancia: todos los seres humanos tienen una única razón y la razón en todos los seres humanos es una. Con ello, Avicena y Avicebrón le sustraen el suelo a la arrogancia de las religiones locales, es decir, a la fe del islam, según la cual fuera de ella solo queda la noche. También, al poder absoluto del cristianismo, representado en las llaves de Pedro que decide quién entra y quién debe quedar fuera del Paraíso. Por ello, Alberto Magno y Tomás escribieron "De unitate intellectus contra Averroistas". El pathos de la tolerancia reivindicado por la Ilustración encontraría en este espíritu de Avicena y Avicebrón su origen.

En tercer y último lugar, se encuentra la relación de materia y forma. Para los escolásticos, la materia es lo caído, lo pasivo, lo que debe ser formado desde fuera, el principio femenino. Dios es, en definitiva, la forma absoluta y la materia solo puede ser gracias a la intervención de aquella. Es así que para ellos, la Iglesia es la única capaz de interpretar correctamente la voluntad divina; Dios habla en su Iglesia y solo algunos privilegiados son capaces de escuchar y difundir dicha palabra. El autoritarismo es, por tanto, inherente a esta cosmovisión. Hemos visto cómo esta relación es inversa en Avicena.

A pesar de que no siempre se puede decir claramente que la izquierda y la derecha han ido en direcciones diametralmente opuestas; en muchos aspectos, incluso han coincidido. Sin embargo Bloch insiste 
en que, en general y en aspectos fundamentales, la base clerical y la apologética defendidas en las universidades escolásticas nos permiten hablar de una derecha aristotélica. Los sistemas católicos de la Edad Media harían de Aristóteles no solo el precursor de Cristo, sino el precursor del sistema feudal-clerical y de su ideología. Un fresco de la escuela de Giotto en la iglesia Santa María Novella de Florencia muestra a Averroes junto a los herejes Arius y Sabelius como totalmente refutado a los pies de Tomás.

Lo que marca realmente la diferencia entre ambos es la forma en que fueron tratados por el poder. La persecución a que fueron sometidos todos los izquierdistas muestra la amenaza que se veía en sus filosofías. El Califa de Bagdad ordenó quemar la Enciclopedia filosófica de Avicena en 1150 , de modo que solo se han conservado fragmentos del texto original. También, los libros de Averroes fueron condenados a la hoguera todavía en vida del filósofo y se prohibió estrictamente enseñar su filosofía. El persa Al-Gazhali había escrito una "Refutación de los filósofos", en la que defendía que la filosofía estaba en contradicción con la religión. Averroes le replicó con una "Refutación de la refutación" en la que defendía la filosofía y su compatibilidad con la religión. El Califa de Córdoba promulgó un edicto que indicaba que Dios creó el infierno para los que enseñaran que solo la razón basta para conocer la verdad. Averroes tuvo que huir. Así, la filosofía acabó convirtiéndose en Oriente en algo tan peligroso como lo fue considerada la ciencia natural en Occidente. Por desgracia, en Oriente, se escolastizó, academizó y dogmatizó la cultura general, la religión y con ello la política, que sufrió un proceso paralelo al de Europa.

\section{III}

Giordano Bruno (junto con Copérnico y Galileo) es el máximo heredero y exponente en Europa de esta tradición naturalista. En él, la forma deja de tener el lugar predominante en favor de la materia. Mucho más la forma que encuentra en un "más allá" su determinación. La materia es autárquica; ella misma produce la riqueza de formas, que es la causa del mundo que percibimos. Solo en esta natura naturans 
vive el artista que forma el mundo y la infinita naturaleza divina teje ella sola permanentemente el vestido infinito de la Naturaleza-Dios natura naturata. La naturaleza nunca es pasiva en Bruno. La materia es la madre de todas las formas; entre materia y forma, no hay una diferencia substancial. Hegel dirá lo siguiente de Bruno: "Esta materia no es sin la efectividad, la forma es la potencia y la vida interna de la materia". Dios no es un momento independiente de la materia, sino que esta tiene a lo pensado bajo el "moviente inmóvil" como su vida propia, a su nivel más elevado.

En 1637, René Descartes publica en francés su Discurso del método. Sabe que está abriendo una ruta nueva para el conocimiento, pero conoce también su tiempo y toma por tanto sus precauciones. Unos años antes, había escrito un libro con el título Mundo. De este libro, que nunca llegó a publicarse y desapareció, quedaron algunos fragmentos y menciones en otras obras. Se parecía demasiado (como sabemos por el mismo Descartes y por los fragmentos que quedan) al que había escrito Galileo y que había sido condenado a la hoguera por el Santo Oficio de Roma. Por ello, Descartes renuncia a publicar su libro y, como no podía quedarse de brazos cruzados, buscó un subterfugio. Así, publicó el Discurso del Método, en que explica las circunstancias de su vida. Explica las dificultades de su viaje filosófico y los principios de su nuevo método de conocimiento. Lo que queda atrás, contra lo que Descartes lucha, son las enseñanzas cómodas e inútiles de sus maestros escolásticos, los jesuitas que se personaban en todos los casos sospechosos de heterodoxia.

Con Descartes suele comenzar la filosofía moderna. El mismo Hegel lo hace. Sin embargo, como hemos visto, Descartes es solo uno de los muchos que estaban trabajando en la misma dirección. Los filósofos europeos comienzan a moverse por ese mismo afán de conocer realmente, es decir, naturalísticamente. Y para ello desarrollan un instrumento indiscutible: la matemática. Esta será su único medio, su método, su propia astucia. Por medio de ella, el ser humano quiere conocer el mundo; en ello, se juega su libertad, su futuro, un mundo mejor. El ser humano entra en su mayoría de edad, como diría Kant en ¿Qué es la Ilustración? 
El Discurso del método es un libro magnífico en el que el autor nos cuenta, entre otras muchas cosas, su decepción con las enseñanzas recibidas que le habían transmitido durante sus estudios en la Flèche. La decepción le lleva a romper con todo lo aprendido y a viajar por Europa. El viaje vuelve a ser la metáfora del conocimiento. Tras Ulises y Magallanes, Descartes la reivindica como fuente inaugural e iniciática. Luego, se retira y se dedica a reflexionar sobre los resultados a los que llegó a partir de un método nuevo, que él mismo desarrolló y cuyo fundamento no era otro que seguir ordenadamente su propio instinto curioso con un instrumento poderoso que era la matemática. Es el viaje de un hombre solitario (no podía ser de otro modo) que vaga entre la niebla; al respecto nos dice lo siguiente: "comme un homme qui marche seul et dans les ténèbres” (Discurso del método, libro 2).

En este obra, Descartes repite varias veces que a él lo que le interesa es conocer realmente. No le interesa la erudición como tal ni publicar para hacerse famoso. Si llega a escribir es porque considera su deber enseñar a los demás lo que ha aprendido, pues sería egoísta conservarlo para él mismo. Resulta realmente sorprendente la humildad y la perseverancia que le mueve en su empresa. Cuenta, por ejemplo, cómo acudía cada día a visitar al carnicero para examinar las entrañas de los animales. Lo hace en una carta a Marsenne (13.11.1639); le cuenta cómo, durante un invierno que pasó en Amsterdam, iba casi cada día a casa de un carnicero a verle matar los animales y se llevaba a su estancia partes de estos que deseaba analizar. Lo hacía en todos los lugares en los que había estado, comenta. Y su conocimiento lo cultiva -dice, en varias ocasiones-, para conducir mejor su vida, su conducta: "Par ce moyen je réussirais à conduire ma vie beaucoup mieux" (Discurso del método, libro 2). No se trata de una curiosidad de cómodo profesor o erudito ajeno al mundo; muy al contrario: se trata de aprender para mejorar la vida ("Du mußt dein Leben ändern”, Rilke) para caminar lo más correctamente (léase racionalmente) posible. Descartes incluso augura una vida más feliz y larga si se siguen sus enseñanzas: "Il me semble voir très evidémment que, si nous nous gardions seulement de certains fautes que nous avons coutume de commetre au régime de notre vie, nous pourrions sans autres inventions parvenir à une vieillesse beaucoup plus longue et plus heureuse que nous ne faisons" (Carta a Huygens, 4 de diciembre de 1937). 
Por cierto, Descartes se considera más aristotélico que los escolásticos. Reivindica, por tanto, a Aristóteles. No reniega de él. Sí de los aristotélicos. En una nota (Descartes, 1970, p. 238), el editor (nada menos que Paul Valéry) habla del aristotelismo de los escolásticos; lo hace para oponer a dicho aristotelismo un "verdadero" aristotelismo. Valéry se centra en el "héroe" Descartes, le impresiona su personalidad, su presencia fuerte en su filosofía, opuesta diametralmente a la estructura impersonal de la escolástica.

Spinoza, al decir de Deleuze, practicó una actitud semejante a la de su predecesor. Humildad, pobreza, castidad son las virtudes que Deleuze le otorga al judío. Son, además, dice, las que Nietzsche le aconseja a todo aquel que quiera hacer filosofía. La creación filosófica es la actividad más sublime, según Deleuze: "Humildad, pobreza y castidad se vuelven de inmediato efectos de una vida particularmente rica y sobreabundante, tan poderosa como para haber conquistado el pensamiento y puesto a sus órdenes cualquier otro instinto" (Deleuze, 1981, cap. 1). Es la que practicó Spinoza: renunciar a todo para encontrar la única verdadera felicidad, la del que libremente se dedica a la filosofía, es decir, a entender el mundo, sin prejuicios, sin límites, sin miedos, sin coacciones políticas ni religiosas. Un segundo aspecto que Deleuze subraya en la filosofía de Spinoza es que pone en el centro de su filosofar al cuerpo. El cuerpo es su objeto central de investigación. Esto le da a Spinoza una actualidad inusitada y lo sitúa en la tradición reivindicada por Bloch. Bien sabía Spinoza a lo que se estaba arriesgando. Fue seguramente el filósofo más odiado y perseguido. La amarga condena y expulsión del círculo judío lo indica claramente. Vale la pena recordar el "Decreto de excomunión" contra Spinoza (1656):

Los dirigentes de la comunidad ponen en su conocimiento que desde hace mucho tenían noticia de las equivocadas opiniones y errónea conducta de Baruch de Spinoza y por diversos medios y advertencias han tratado de apartarlo del mal camino. Como no obtuvieran ningún resultado y como, por el contrario, las horribles herejías que practicaba y enseńaba, lo mismo que su inaudita 
conducta fueron en aumento, resolvieron de acuerdo con el rabino, en presencia de testigos fehacientes y del nombrado Spinoza, que éste fuera excomulgado y expulsado del pueblo de Israel, según el siguiente decreto de excomunión: Por la decisión de los ángeles, y el juicio de los santos, excomulgamos, expulsamos, execramos y maldecimos a Baruch de Spinoza, con la aprobación del Santo Dios y de toda esta Santa comunidad, ante los Santos Libros de la Ley con sus 613 prescripciones, con la excomunión con que Josué excomulgó a Jericó, con la maldición con que Eliseo maldijo a sus hijos y con todas las execraciones escritas en la Ley. Maldito sea de día y maldito sea de noche; maldito sea cuando se acuesta y maldito sea cuando se levanta; maldito sea cuando sale y maldito sea cuando regresa. Que el Señor no lo perdone. Que la cólera y el enojo del Señor se desaten contra este hombre y arrojen sobre él todas las maldiciones escritas en el Libro de la Ley. El Señor borrará su nombre bajo los cielos y lo expulsará de todas las tribus de Israel abandonándolo al Maligno con todas las maldiciones del cielo escritas en el Libro de la Ley. Pero ustedes, que son fieles al Señor vuestro Dios, vivid en paz. Ordenamos que nadie mantenga con él comunicación oral o escrita, que nadie le preste ningún favor, que nadie permanezca con él bajo el mismo techo o a menos de cuatro yardas, que nadie lea nada escrito o trascripto por él.

La historia se encargaría de reponer a Spinoza en el sitio que le correspondía. Sin él, ni el Idealismo Alemán ni la filosofía francesa actual hubieran llegado a donde llegaron.

Spinoza cree en la potencia de la vida. Y la vida no es una cuestión puramente teórica. "Es una forma de ser" (Deleuze, 1981, p. 20). Las virtudes antes citadas no mutilan la vida, son "potencias que la abrazan y la penetran" (Deleuze, 1981, p. 22). "Ningún filósofo fue más digno, pero, a pesar de ello, ninguno fue más injuriado y odiado" (Deleuze, 1981, p. 27). En nombre de la vida, Spinoza denuncia la "conciencia", los "valores" y las "pasiones tristes". En esto, ve Deleuze su gran afinidad con Nietzsche. Frente a la conciencia, Spinoza propone el modelo del cuerpo, pero no se trata de invertir el modelo e imponer la ley del cuerpo a la conciencia, sino de conocer los poderes del cuerpo para "descubrir paralelamente los poderes del espíritu que escapan a 
la conciencia" (Deleuze, 1981, p. 27). Michel Foucault, en sintonía con Deleuze, afirma que el cuerpo es un "campo político sobre el que operan las relaciones de poder como una presa inmediata: lo cercan, lo marcan, lo doman, lo someten a suplicio, lo fuerzan a unos trabajos, lo obligan a unas ceremonias, exigen de él unos signos" (Foucault, 1976, p. 32).

\section{III}

España cerró las puertas al mundo islámico al expulsarlo de ella. Esto fue especialmente trágico, porque España por su situación geopolítica estaba llamada a ser el país bisagra entre los países islámicos (y hebreos) y Europa (sin olvidar Latinoamérica). Los llamados Reyes Católicos se erigieron en abanderados de una reacción contra cualquier tipo de disidencia a la recta doctrina católica romana. Expulsaron manu militari a judíos y árabes, y pusieron en marcha la terrible y temida Inquisición que llegó hasta el siglo xix. Así, acabaron de un plumazo con una rica tradición que hubiera podido construir una base humanista para un mundo culturalmente tolerante y mutuamente enriquecedor.

Esto empobreció a España y la aisló de los países colindantes, a pesar de -o quizá por- ser el país militarmente más potente de la época. Lo militar y lo cultural siempre se han llevado mal. Este aislamiento supuso un claro retroceso con respecto a los países europeos que caminaban hacia la Ilustración y la revolución burguesa, es decir, hacia la Modernidad y el progreso. La gran contradicción de una España potente militar y clericalmente y de un creciente retroceso en lo cultural se va a ir acrecentando hasta llegar a la gran crisis de 1898 en que España vuelve a quedarse sola, sin sus colonias y sumida en una decadencia cultural que hace reaccionar a toda una generación de intelectuales, con Miguel de Unamuno a la cabeza, que tratan de salvar a España in extremis.

Todavía en el siglo xix, Balmes, en su obra Filosofía fundamental, intenta asentar los principios filosóficos por los que había de discurrir el catolicismo tradicionalista, opuesto al liberalismo europeo; decía que la obra de Kant estaba llena de errores trascendentales, por lo que se 
trataba de un grave e inminente peligro que era necesario combatir, pues sobre ella se asientan, a su entender, los sistemas de Fichte, Schelling y Hegel, es decir, el Idealismo alemán. "La Crítica de la razón pura es la ruina de toda razón; esta se examina a sí propia para suicidarse" (Balmes, 1922, p. 470). Balmes se centró en acabar con Kant, para así, creía, acabar con todos sus seguidores. Tenía razón. Kant es la Ilustración europea, decía Horkheimer, pero aun así Balmes solo consiguió aislar y ahondar más a Espańa en su retraso cultural. Tampoco sirvió de mucho el empeño de los "liberales" del siglo xix que introdujeron en España (por diversas circunstancias más o menos casuales) a un desconocido como era Krause en su mismo país, Alemania.

En el arriba citado prólogo de Menéndez y Pelayo a la obra de Ibn Tofail (Abentofail), leemos lo siguiente:

La obra filosófica más original y profunda de la literatura arábigohispana, [...] a saber, la famosa novela del andaluz Abucháfar (o, como otros dicen, Abubéquer) Abentofail, Hay Benyocdán, conocida generalmente con el título de El filósofo autodidacto. Mengua era, en verdad, para España, madre de tan ilustre pensador, no poseer todavía en su lengua vulgar este libro celebérrimo, que ya en el siglo XIv había sido traducido al hebreo por Moisés de Narbona, y que los occidentales podían leer en la versión latina de Pococke, en tres diversas traducciones inglesas (una de ellas, la de Jorge Keith, muy popular, como libro de edificación, entre los cuáqueros), en dos alemanas, debida la segunda de ellas a la docta pluma de Eichhorn (1783); en una holandesa, y quizá en otras que no han llegado a nuestro conocimiento. Libro tan conocido en los fastos de la filosofía, tantas veces analizado y comentado, no sólo por los arabistas, sino por cuantos se interesan en la historia del pensamiento humano; libro calificado por Renán de "acaso el único de la filosofía oriental que hoy pueda ofrecernos un interés permanente y distinto del histórico", bien merecía volver a la patria de su autor en traje castellano.

En la lectura que hace Menéndez y Pelayo del libro de Ibn Tofail, deja clara su postura de que la tradición española poco o nada tiene que ver con la tradición árabe. Se trata de un libro "tan poco 
musulmán en el fondo"). Nada que ver con el "hórrido galimatías" en que han convertido a dicho texto Averroes y Avicena en las versiones latinas. La cultura y la filosofía españolas son cristianas. No son, por tanto, tampoco europeas ni ilustradas: son "eternas". Abentofail es "de los nuestros", aunque escribiera en otra lengua y tuviera otra religión. "Los tres grandes filósofos de la España árabe, Avempace, Abentofail, Averroes, eran, no sólo musulmanes poco fervientes, sino librepensadores apenas disimulados, a quienes sus correligionarios miraron siempre con aversión, y cuyas obras procuraron destruir”. La lectura sesgada y rancia que hace Menéndez y Pelayo tanto del libro como de toda la cultura y la filosofía se ve claramente en el texto completo, que apenas necesita comentario:

No indigno de los buenos modelos es, en esta parte, el trabajo del Sr. Pons; y como la obra de Abentofail es de suyo tan interesante y está además tan pulcramente traducida, creo que no han de faltarle lectores, aun entre aquellas personas cultas que no siendo arabistas ni filósofos de profesión, se han de ver agradablemente sorprendidos al encontrarse, no con el hórrido galimatías de las versiones latinas de Averroes y Avicena, sino con un libro tan ameno en su forma, tan elevado e idealista en su tendencia, tan poco musulmán en el fondo, tan humano en las cuestiones que suscita, y que son las mismas que eternamente agitarán nuestra razón, no sé si por su mayor excelencia o por su mayor castigo. $\mathrm{Y}$ ciertamente debemos gloriarnos de que tal pensador naciera en España, sin que sean obstáculo para que le contemos entre los nuestros su religión ni su lengua, pues precisamente su pensamiento poco tiene de semítico; y es cosa ya admitida por todo el mundo que la secta filosófica a que pertenecía Abentofail, y cuyas raíces están en la escuela alejandrina, sólo fue árabe por la lengua, vivió en hostilidad perpetua, aunque latente, con el Islam, que acabó por proscribirla y exterminarla; y tampoco floreció nunca entre los árabes propiamente dichos, ni entre los africanos, sino en pueblos indo-europeos, como Persia y Andalucía, donde existía una gran masa de renegados indígenas, herederos de una cultura anterior, y donde hubo períodos de profunda indiferencia religiosa y notable quebrantamiento de la ortodoxia muslímica. Los tres grandes 
filósofos de la España árabe, Avempace, Abentofail, Averroes, eran, no sólo musulmanes poco fervientes, sino librepensadores apenas disimulados, a quienes sus correligionarios miraron siempre con aversión, y cuyas obras procuraron destruir, habiéndolo conseguido o poco menos respecto de las del primero, cuyo tratado más importante, el Régimen del solitario, no conocemos más que por el extracto de un judío. De Abentofail [328] no se ha salvado más que su novela. Averroes, el menos original de los tres, tuvo por circunstancias fortuitas inmensa popularidad en las escuelas cristianas, grandes discípulos y grandes adversarios: a la sombra de su doctrina se educaron todos los incrédulos de la Edad Media: todavía en el siglo Xvi, en pleno Renacimiento, su nombre y su doctrina, bien o mal interpretada, suscitaba tormentas en el estudio de Padua; pero con toda esta celebridad en el mundo occidental contrasta la desdeñosa indiferencia de los árabes, que se acuerdan de Averroes como médico, no como filósofo, y que han dejado perecer los originales de la mayor parte de sus obras, siendo forzoso buscar en traducciones hebreas o latinas (derivadas por lo común del hebreo) casi toda la inmensa y enciclopédica labor del sabio maestro de Córdoba, del más célebre de los comentadores del Estagirita. Con razón se ha dicho que la filosofía es un episodio en la historia de los árabes. Y esto no por incapacidad nativa, ni por los límites que arbitraria y exageradamente han querido imponer algunos historiadores al genio de los pueblos semíticos, sino por la contradicción palpable e insoluble entre el dogma musulmán y una filosofía a medias peripatética, a medias neo-platónica, nacida y desarrollada en el seno del paganismo clásico, con espíritu de libérrima indagación racional, y cuyas tesis, ya fuesen panteístas, ya dualistas, ora afirmando la eternidad de la materia, ora la unidad del entendimiento agente, era imposible concordar con los dogmas de la unidad de Dios y de la inmortalidad personal. Presentada la ciencia filosófica en tan radical oposición con la creencia, tenía que sucumbir en la lucha, y si algo de ella se salvó del naufragio, fue porque algunos de sus adeptos, huyendo de la escueta forma dialéctica, procuraron envolver sus audaces lucubraciones en las nieblas de la alegoría y entre los velos del misticismo, que es el caso del Hay Benyocdán; al paso que otros, o por disimulación y cautela, o por sincero y fervoroso afán de sacar incólume la ley mahometana del conflicto con la razón especulativa, combatían 
la filosofía con sus propias armas, como Algazel, cuya influencia fue enorme en Espańa; y encontraban puerto de refugio contra el escepticismo en el iluminismo de los sufies, como el recientemente descubierto filósofo murciano Mohidín, cuyas analogías con Raimundo Lulio [329] han señalado muy atinada y sagazmente los Sres. Ribera y Asín.

Estamos, pues, en los antípodas de Bloch. Miguel de Unamuno y su generación del 98 fueron los primeros que trataron de rescatar a España de esta miseria, que luego Franco se encargaría de aplastar nuevamente. Una posterior democracia aguada no supo acabar con los fantasmas del pasado, como se ve en las actuales polémicas políticas.

\section{V \\ A modo de conclusión provisional}

Alain Badiou hace del mismo Platón un filósofo "naturalista" al entender la idea platónica no como externa y alejada de la materia, sino que la materia misma lleva ya en sí el principio de transformación, el principio vital; en definitiva, la idea misma. Esta sería inmanente a la materia. Sería, pues, un antecesor de esa izquierda aristotélica. Badiou reivindica, por tanto, una nueva lectura de Platón en el mismo sentido de la izquierda aristotélica de Bloch, en líneas generales. Podríamos decir que Platón propuso, antes de Aristóteles, un modo naturalista de entender la filosofía, incluso de un modo más radical que Aristotéles.

El gran filósofo griego Platón, que pone las bases firmes de su filosofía y el último filósofo del Idealismo Alemán, Hegel, el que recoge lo más granado de este movimiento imprescindible en filosofía son el comienzo y el final de un gran círculo filosófico. Hegel es toda la filosofía, podríamos decir con Adorno (aunque él se refiere a Beethoven: Beethoven es toda la música). Hegel es el filósofo al que Bloch va a dedicar sus mayores esfuerzos. Lo va a reivindicar como el autor moderno que es capaz de llevar a cabo una lectura radical de toda la tradición occidental y poner las bases de una filosofía definitivamente nueva. Así lo entiende la tradición crítica y también la filosofía francesa 
actual. Aún no hemos llegado a Hegel, creen muchos. Por ejemplo, Susan Sontag, cuando en "The Pornographic Imagination” (1962) afirma lo siguiente:

Hegel made perhaps the grandest attempt to create a post-religious vocabulary, out of philosophy, that would command the treasures of passion and credibility and emotive appropriateness that were gathered into the religious vocabulary. But his most interesting followers steadily undermined the abstract meta-religious language in which he had bequeathed his thought, and concentrated instead on the specific social and practical applications of his revolutionary form of process-thinking, historicism. Hegel's failure lies like a gigantic disturbing hulk across the intellectual landscape. And no one has been big enough, pompous enough, or energetic enough since Hegel to attempt the task again.

Y Michel Foucault afirma lo siguiente de Hegel en su discurso de entrada en la Academia, publicado en 1971 con el título L'ordre du discours:

Mais je pense que ma dette, pour une très large part, va à Jean Hyppolite. Je sais bien que son oeuvre est placée, aux yeux de beaucoup, sous le règne de Hegel, et que toute notre époque, que ce soit par la logique ou par l'épistémologie, que ce soit par Marx ou par Nietzsche, essaie d'échapper à Hegel: et ce que j'ai essayé de dire tout à l'heure à propos du discours est bien infidèle au logos hégélien.

Mais échapper réellement à Hegel suppose d'apprécier exactement ce qu'il en coûte de se détacher de lui ; cela suppose de savoir jusqu'où Hegel, insidieusement peut-être, s'est approché de nous ; cela suppose de savoir, dans ce qui nous permet de penser contre Hegel, ce qui est encore hégélien ; et de mesurer en quoi notre recours contre lui est encore peut-être une ruse qu'il nous oppose et au terme de laquelle il nous attend, immobile et ailleurs. 
Hegel rescata a Aristóteles y a Spinoza del olvido en que los dejó la filosofía kantiana. Termina su Enciclopedia con una cita de Aristóteles. Y con Spinoza Hegel pone de nuevo la materia, el cuerpo en el centro del filosofar, contra el formalismo kantiano. O, mejor dicho: leyendo desde dentro el manco que suponía dicha filosofía. Para Hegel es la vida el principio mismo de la filosofía.

Por ello, cuando Marx dice en sus Thesen über Feuerbach: "Der Hauptmangel alles bisherigen Materialismus [...] ist, daß der Gegenstand, die Wirklichkeit, Sinnlichkeit, nur unter der Form des Objekts oder der Anschauung gefaßt wird' (Tesis 1), debía haber añadido lo siguiente: Hegel es el primero que entiende el objeto, la realidad, la sensibilidad como actividad humana sensible, como praxis. El comienzo del cuarto capítulo de la Fenomenología no puede leerse de otro modo. Marx se dejó probablemente despistar por las lecciones de Schelling en Berlín.

La cita de Adorno al comienzo de este artículo: "La libertad consiste en ir más allá de aquello con lo que el pensamiento conecta ofreciéndole resistencia. La necesidad de hacer elocuente el sufrimiento es la condición de toda verdad. Pues el sufrimiento es objetividad que pesa sobre el sujeto; aquello que él experimenta como lo más propiamente subjetivo, su expresión, está mediado objetivamente" (Trad. de J. A. Zamora), podría valer de comentario para el citado cuarto capítulo de la Fenomenología.

Horkheimer en "la función social de la filosofía" (1940), dice lo siguiente de Hegel, que puede valer para toda la filosofía:

Hegel, a quien en muchos respectos tanto debemos, estaba tan lejos del malhumorado repudio de situaciones específicas, que el rey de Prusia lo llamó a Berlín para que inculcase en los estudiantes la debida lealtad y los inmunizase contra toda oposición política. Hegel hizo todo lo que pudo en ese sentido y proclamó al Estado prusiano "realidad efectiva de la idea ética" sobre la Tierra, pero el pensamiento es algo muy particular. Para justificar al Estado prusiano, Hegel debió educar a sus alumnos en la superación del carácter unilateral y limitado del entendimiento humano común, debió hacerles inteligir la conexión recíproca entre todas 
las condiciones conceptuales y reales. Además, debió enseñarles a comprender la historia humana en su compleja y contradictoria estructura, a analizar las ideas de libertad y justicia en la vida de los pueblos y a reconocer que estos sucumben cuando sus principios de libertad y justicia ya no resultan adecuados y la época está madura para nuevas formas sociales. El hecho de que Hegel tuviera que iniciar a los estudiantes en el pensar teórico trajo consecuencias muy dudosas para el Estado prusiano. Al final, ello hizo que esta institución reaccionaria sufriera mayores daños que las ventajas que obtuvo de su glorificación formal. La razón es un aliado muy poco firme de la reacción. Menos de diez años después de la muerte de Hegel (durante todo este tiempo su cátedra permaneció vacante), el rey de Prusia buscó un sucesor que luchara contra la "siembra de discordia del panteísmo hegeliano" y contra "la insolencia y el fanatismo de su escuela”. 


\section{Bibliografía básica}

Adorno, Theodor-W. (1996). Negative Dialektik. GS 6. Suhrkamp, Frankfurt.

Bloch, Ernst (1963). Avicenna und die Aristotelische Linke. Suhrkamp, Frankfurt [1952].

Deleuze, Gilles (1981). Spinoza: Filosofia práctica. Tusquets Editores, Barcelona [1971].

Descartes, René (1937). Discours de la méthode pour bien bien conduire sa raison et chercher la vérité dans les sciences. [1637].

Foucault, Michel (1976). Vigilar y castigar. Siglo Veintiuno Editores, México [1975].

Horkheimer, Max (1974). La función social de la filosofía. Amorrotu Editores, Buenos Aires [1940].

Horkheimer, Max (1946). The Eclipse of Reason. Oxford University Press, New York (traducido al alemán como Zur Kritik der instrumentellen Vernunft 1967).

Insausti, Xabier (2019). Hegel and Aristotle: Aristotle is the True Master of Humanity (Aristoteles ist der eigentliche Lehrer des Menschengeschlechts). In: WCP 2016: THE PHILOSOPHY OF ARISTOTLE Vol v.

Rancière, Jacques (1987). Le maître ignorant: Cinq leçons sur l'emancipation intellectuelle. Fayard, París.

Sontag Susan (1961). Against Interpretation. Dell Publishing, New York. 